Preprint. Final version appears as:

Morgan, R., Cohen, J., McGookin, I., Murly-Gotto, J., O’Connor, R., Muress, S., Freudiger-Bonzon, J. \& Bull, P. (2009) The relevance of the evolution of experimental studies for the interpretation and evaluation of some trace physical evidence. Science and Justice. DOI 10.1016/j.scijus.2009.02.004

\title{
The relevance of the evolution of experimental studies for the interpretation and evaluation of some trace physical evidence
}

Morgan, R., Cohen, J., McGookin, I., Murly-Gotto, J., O’Connor, R., Muress, S., FreudigerBonzon, J. \& Bull, P.

Communicating author: Ruth Morgan

Ruth.morgan@ucl.ac.uk

Tel: +442031083037

Fax: +44 2031083088 


\title{
The relevance of the evolution of experimental studies for the interpretation and evaluation of some trace physical evidence
}

\author{
Morgan, R., Cohen, J., McGookin, I., Murly-Gotto, J., O’Connor, R., Muress, S., Freudiger- \\ Bonzon, J. \& Bull, P.
}

\begin{abstract}
In order for trace evidence to have a high evidential value, experimental studies which mimic the forensic reality are of fundamental importance. Such primary level experimentation is crucial to establish a coherent body of theory concerning the generation, transfer and persistence of different forms of trace physical evidence. We contend that the forensic context, at whatever scale, will be specific to each individual forensic case and this context in which a crime takes place will influence the properties of trace evidence. It will, therefore, be necessary in many forensic cases to undertake secondary level experimental studies that incorporate specific variables pertinent to a particular case and supplement the established theory presented in the published literature. Such studies enable a better understanding of the specific forensic context and thus allow more accurate collection, analysis and interpretation of the trace physical evidence to be achieved.
\end{abstract}

This paper presents two cases where the findings of secondary level experimental studies undertaken to address specific issues particular to two forensic investigations proved to be important. Specific pre-, syn- and post-forensic event factors were incorporated into the experimental design and proved to be invaluable in the recovery, analysis and in achieving accurate interpretations of both soil evidence from footwear and glass trace evidence from a broken window.

These studies demonstrate that a fuller understanding of the specific context within which trace physical evidence is generated and subsequently collected, as well as an understanding of the behaviour of certain forms of trace physical evidence under specific conditions, can add evidentiary weight to the analysis and interpretation of that evidence and thus help a court with greater certainty where resources (time and cost) permit.

Keywords: experiments, soil, glass, persistence, interpretation 


\section{Introduction}

The value of trace physical evidence lies not only in its presence at a crime scene or on a suspect, but in the ability of the forensic scientist to collect, analyse, interpret and present the derived findings appropriately and meaningfully within the forensic context specific to each investigation [1]. To this end experimental work has been undertaken to provide the necessary context, and to achieve meaningful interpretations of trace physical evidence for the courtroom. However, whilst this primary level of experimentation has established a good body of theory relevant to different forms of trace physical evidence [2-5] we suggest here that there is a need to establish a secondary level of experimentation which is customised to a particular crime event or scene which builds upon that pre-existing body of theory. When such secondary level experimentation is undertaken, a specific framework can be established to carry out accurate and meaningful interpretation of trace physical evidence recovered from a particular crime scene or suspect.

In the developing field of geoforensics much experimental work is being undertaken [6-12] to establish a body of theory. Similarly to other forms of trace physical evidence, it is not only crucial that such work is repeated (so as to establish variability) but that work is also undertaken that is pertinent to and as closely mimicking forensic reality as possible. Only then will the general nature of particular forms of geoforensic evidence under certain situations be established and a body of theory developed so as to enable the best procedures and protocols to be established for the collection, analysis, interpretation and presentation of evidence to the court. Each forensic case is different, it will have different variables and impinging external factors, and so this task is not easy. Indeed, whilst established protocols would be desirable, this inherently individual nature of each forensic case ensures that such an outcome can only be achieved (if at all) by the intensive use of secondary level experimental work.

The complexity of even the simplest situations provides a salient lesson. For example, very many experimental studies will be necessary to begin to establish the character of trace geoforensic evidence on the sole of a shoe. There are many variables to consider; establishing how soils/sediments transfer onto the sole, how 
they behave on the shoe during walking or running on different surfaces, under different conditions and on different shoe sole types and patterns, how soils/sediments from different sources interact on that sole and how long those sediments may persist. Understanding the forensic context of the sole of a shoe will enable far greater precision not only at the collection stage, but will allow the most meaningful analyses to be undertaken on trace material recovered and thus the most accurate interpretation of that evidence [1]. However, the secondary level of experimentation which takes into account the individual variables pertinent to a specific forensic investigation is also crucial to enable an accurate understanding of the individual context within which geoforensic evidence is found and to thus allow pertinent analysis and interpretation in that specific situation.

This paper seeks to provide two examples where the analysis and interpretation of trace evidence required detailed and repeated secondary level experimentation in order to understand the specific forensic context. Whilst some of the work contained herein presents data similar to that presented in the published literature, the experiments were designed to mimic exactly the conditions of each crime scene and thus provide the scope for far more accurate interpretation of the trace physical evidence recovered in each case.

\section{Experimental Studies}

\subsection{Case 1: Persistence of trace geoforensic evidence on footwear after washing}

A case arose during a criminal investigation where a very important part of that enquiry concerned the footwear belonging to a suspect. Soil samples from a body deposition site could not be excluded from soil samples recovered from a vehicle after elemental chemical, quartz grain surface texture, mineralogy and colour analyses had been undertaken. However, the suspect stated that he had not been in the driver's seat. It was therefore, necessary to investigate whether it were possible to exclude the footwear belonging to the suspect from having any associated geoforensic material that could also not be excluded from having derived from the same provenance as the soil/sediment evidence collected from the driver side of the vehicle and the body deposition site. The significant variable in this case was that the footwear had been 
washed in a washing machine and appeared to be clean with no geoforensic material visible.

It became apparent that there was no established body of literature concerning the preservation of soil on footwear after washing. Therefore, an experiment was designed and carried out to test whether it was possible for soil/sediment material to persist on footwear that had undergone cleaning in a washing machine. The suspect was understood to have washed the shoes with other items of clothing and so the experiment was designed in which new and previously unworn, but muddied, training shoes were washed in a standard washing machine with a new and previously unworn cotton t-shirt and pair of jeans on a normal cycle (at $\left.40^{\circ} \mathrm{C}\right)$. This experiment was repeated three times with a new pair of training shoes and clothing for each experimental run and all the items were then dried and trace evidence recovered for analysis by binocular microscope (see figure 1). After the washing cycle, the footwear appeared to be clean and it was only when the training shoe inner was removed that the majority of the geoforensic evidence was recovered.

The results revealed that the majority of particulates recovered from the footwear and clothing were mineral particulates (the majority of which were quartz grains) (figure 1). For the mineral particulates the $<10 \mu \mathrm{m}$ fraction constituted on average $61.5 \%$ of the material recovered from all the items (standard deviation 17.8), indeed with $28.4 \%$ being $10-100 \mu \mathrm{m}$, only $10.1 \%$ of the particulates were larger than $101 \mu \mathrm{m}$ (see figure $2)$. It is interesting to note however, that these larger particulates $(>101 \mu \mathrm{m})$ were generally recovered from the training shoes $(15.3 \%$ in the left trainer, $12.5 \%$ in the right trainer) in comparison to only $6.1 \%$ and $6.7 \%$ on the T-shirt and jeans respectively).

In addition, it is important to note that the soil/sediment material present on the training shoes before the washing process was not only retained in the training shoes themselves but was also transferred to the clothing present in the same drum.

Whilst this was a small experimental study $(n=3)$, it provided pertinent information for this forensic investigation. By demonstrating that washed training shoes may 
retain geoforensic material and establishing which locations on and within the shoe are most likely to yield such evidence, it was possible to recover evidence from the shoes submitted for analysis in this case. It was possible to undertake a number of analytical tests on that trace evidence (mineralogy, colour, quartz grain surface texture analysis) with the result that it was not possible to exclude the sediment retained within the training shoes from having derived from the same provenance as the soil/sediment collected from the body deposition site and from within the vehicle (following the philosophical approach promoted by Walls [13] and later by Morgan and Bull [14]). The experimental work provided a context in which to couch the results of the analysis of the geoforensic material and again gave greater evidential weight to the findings. Additionally, it enabled a more precise interpretation of those results to be reached in the context of the specific forensic case in question.

\subsection{The generation, transfer and persistence of glass particulates}

During the course of a particular crime, the perpetrator(s) smashed a window to gain access to a property. The perpetrator(s) then climbed through the window frame to commit the crime and then made their escape out of the property along the same route before making their way back to a vehicle which was subsequently recovered. It became very important during the analysis of the trace evidence recovered to establish the nature of the transfer of glass particulates from a broken window pane onto the person smashing it, the transfer to and persistence of that glass on the suspect(s) and the vehicle and finally also the persistence of such trace particulate evidence within the vehicle after vacuum cleaning. These three attributes were significant aspects of this case as the suspect who had been apprehended did not have any glass particulates present on either his clothing or his vehicle. This lack of trace evidence was attributed to cleaning of the clothing and vehicle after the crime had been committed. Therefore, assessing these three attributes of the trace physical evidence was considered to be crucial for a valid interpretation of the evidence to be reached and for an accurate crime scene reconstruction to be established.

\subsubsection{Literature Review}

There is a wealth of well established and accepted published work concerning the subject of glass fragments within a forensic context that provides a thorough 
theoretical basis for the analysis and interpretation of glass evidence [2] so only a brief summary is provided here.

\section{The generation of glass fragments}

When float glass is broken, fragments of glass are displaced mechanically (where the smashing instrument pushes large pieces of glass out of the window) and also as a result of fragmentation from both outer and inner surfaces of the glass pane due to the force applied in the smashing action. Whilst forward fragmentation is readily observed, it was not until 1967 that backward fragmentation of glass particles was established through the use of high-speed photography [15]. Nelson and Revell [15] observed backward fragmentation every time a window pane was broken and whilst the majority of particles were deposited within 4-5 feet $(1-1.5 \mathrm{~m})$ of the window, some particles travelled up to 10 feet $(3 \mathrm{~m})$. Pounds and Smalldon [16] investigated the number and size of glass fragments that reached the floor at varying distances behind the point of impact. They demonstrated that different methods of smashing the window pane had little effect on the resulting fragmentation and distribution of glass particles. Indeed, they established that more small fragments $(<1 \mathrm{~mm})$ were produced than larger fragments $(>1 \mathrm{~mm})$. This was subsequently confirmed by Luce et al. [17].

In terms of the spatial distribution of glass particles undergoing backward fragmentation following the breakage of a window pane, Locke and Unikowski [18] undertook replicate experiments. They found that the manner in which particles were scattered varied according to their size. Small fragments of glass were seen to fall more uniformly over the whole area than the larger fragments. In addition, the larger fragments were more likely to be deposited directly behind the point of breakage, whilst the small fragments were found to be deposited both behind and to the sides of the point of breakage. In addition a rapid decline in the smallest particles recovered (of a range between $0.5-0.25 \mathrm{~mm}$ ) as the distance increased from the window concurred with the work of Pounds and Smalldon [16] and subsequently, Allen and Scranage [19] and Hicks et al. [20]. 
Glass fragments may be transferred onto clothing by both primary (from backward fragmentation of a window pane when it is smashed) and secondary transfer (if clothing makes contact with the broken glass debris) ([19]: 236). Hicks et al. [21] found that the number of glass fragments transferred by backscattering is dependent upon the distance of the person from the window pane and Allen and Scranage [19] subsequently found that the greatest amount of glass could be found on dummies that were within $1 \mathrm{~m}$ of the window pane when it was broken. They considered that in terms of secondary transfer of glass particulates onto clothing, that it was 'easy to imagine how glass fragments on the broken edges of a window pane might be transferred to clothing' as a suspect reached or climbed through a broken window ([19]: 173). Indeed, Allen et al. [22] recovered an average of 22 glass fragments from a subject after stepping through a smashed window and attempting not to touch the edges of the frame.

An additional aspect of the transfer of glass particulates to clothing which is pertinent to this study is that of subsequent transfer. Allen et al. [23] undertook an experimental study to establish whether glass particulates from clothing (which had been transferred by primary and secondary means) could be recovered from a vehicle that was used by the subject who had smashed a window pane. After the car ride 1030 glass fragments were recovered from the clothing of the subject (mainly 0.1$0.25 \mathrm{~mm}$ ) and a small number (on average 5-9 particles) were recovered from the interior vehicle mat. Indeed, they also noted that 'occasional fragments were recovered from the car seat' ([23]: 195).

\section{The persistence of particulates on clothing}

A wide range of experimental studies have been undertaken to establish the persistence over time of a number of different types of trace particulates on clothing (for fibres: [24-32]; foam: [33-35]; pollen and soil: [36]; glass: [21, 22, 23, 37]). In general a two-stage decay curve has been demonstrated for each form of particulate evidence following the original study by Pounds and Smalldon [16]. The first stage of decay occurs when initially the larger, more loosely bound particulates are shed rapidly. This is followed by the subsequent (second stage) loss of the smaller and more tightly bound particles at a slower rate. 
The number of hours that particulates can persist on clothing is considerable. Pollen has been demonstrated to remain for at least 647 hours (approximately 27 days) on different types of clothing [36]. A similar study on glass particulates observed the persistence of glass particulates on items of clothing eight hours after smashing a window pane [21].

\section{The tenacity of particulates on vehicle seats following cleaning}

There have, as yet, been no experimental studies published concerning the tenacity of glass particulates on vehicle seats following vacuum cleaning. There are also no studies assessing the differential tenacity of other forms of trace evidence that may be present with the glass particulates.

\subsubsection{Experimental Studies}

The general principles of glass particulate generation, transfer and subsequent persistence and secondary transfer are therefore, well documented. However, it became very important in order to interpret the trace evidence recovered in this case meaningfully, to carry out three experimental studies (each of which was repeated) which addressed

a. the nature of glass particulate generation from a window of the specific dimensions of the window in question in this case;

b. the nature of their transfer and persistence on clothing and vehicle seats;

c. and their tenacity on those vehicle seats after vacuum cleaning.

Experiment 1: the distribution of glass particulates produced by the smashing of a glass window pane.

In order to test the distribution of glass fragments following the smashing of a window, a rig was set up with a window pane mounted within the window frame recovered from the crime scene (as discussed above). Sheets of A4 paper were individually numbered, weighed and placed on the floor in front and behind the window to collect any glass particulates that were produced when the window pane was smashed. The window was then smashed by means of a pendulum system to ensure uniformity between each run and a rock that very closely resembled the rock 
used by the perpetrator. Each piece of paper was then collected and weighed in order to produce a rose diagram to depict the spatial distribution of glass fragments (by weight) deposited each side of the window (Figure 3). The experiment was repeated twice with $6 \mathrm{~mm}$ width salvaged glass panes (so as to introduce the age of the glass to the variables studied previously by Locke and Unikowski [38]) (Figure 3 A and B); twice with new $6 \mathrm{~mm}$ width glass panes (Figure $3 \mathrm{C}$ and D); and 6 times with new $4 \mathrm{~mm}$ width glass panes (Figure $3 \mathrm{E}-\mathrm{J}$ ).

Figure 3 shows that the spatial distribution of glass fragments (both forward and backward) was visually similar for each experiment regardless of the width or age of the glass. On average 32.9\% (standard deviation 9.6) of the glass particles produced were deposited backwards towards the person smashing the window pane. As these computations are derived from glass fragment weight, and since the particle size of the glass fragments ranged from tens of millimetres to sub-micron size, exponentially more small particles of glass were produced than large fragments and this is in accord with comments in the published literature [17-18].

\section{Experiment 2: the transfer of glass onto clothing.}

A second experiment was then carried out to establish whether or not glass fragments transfer onto the clothing of a person who smashes a window pane. The experimenter, wearing brand new clothing (similar to that of the suspect) and standing within $0.5 \mathrm{~m}$ of the window frame, smashed the window pane in a similar manner for each experiment. For each repetition, a new set of clothing was worn. Both experiments utilised the actual window frame from the case in question and this was set up in accordance with the conditions found at the crime scene at a height of $1.2 \mathrm{~m}$ from the ground.

The experimenter who smashed the glass wore a brand new long-sleeved cotton t-shirt and cotton trousers. The t-shirt was divided into 5 equal strips for subsequent taping (thus the counts generated from each strip represented $20 \%$ of the area of the garment). The window pane was then broken with a hand-held rock and the first strip on the t-shirt was taped. The experimenter then took two 5 minute walks followed by two 5 minute runs. After each period of activity a strip of the t-shirt was taped. 
Finally, the t-shirt was washed in a clean washing machine, dried, and the whole garment was then taped. The experiment was then repeated using another similar window pane and a brand new set of identical clothing. The numbers of particulates recovered from the clothing are presented in Table 1 and the decay curve is presented in Figure 4. These figures show that glass particulates are transferred onto the clothing with 12 particulates being recovered from the first taping following the smashing of the first pane, and 34 particulates recovered after the smashing of the second pane. After a five minute walk wearing the same clothing a large number of the particulates had been shed (in accord with the published literature for other trace particulates [21, 22, 23, 36, 37]. Further running and walking (tapings 3-5 in Table 1 and Figure 4) shows a more linear and slower reduction in particulates retained on the clothing. Remarkably, it was still possible to find a glass particulate on the clothing that had undergone a washing and drying cycle in both experiments.

These results demonstrate that glass fragments are transferred onto the clothing following the breakage of a window pane. They also demonstrate the persistence of the transferred glass particulates on clothing over time and after different levels of activity and that glass particulates exhibited the classic decay of trace evidence that has been documented for fibres, foam, hair, pollen and soil (all in accord with the established theory, see above). The recovery of albeit a single glass particulate in each experimental run after the garment had been washed and dried is noteworthy and tends to concur with the preliminary findings of Bull et al. [36] for pollen particulates. This is of course only a preliminary experiment and further work needs to be done to ascertain the wider significance of such a finding on clothing that has been washed. It does however, hint at the possibility of the particulate retention on clothing that has been washed.

Experiment 3: the tenacity of glass particulates and fibres on vehicle seats following vacuum cleaning.

A third experiment was designed to test whether glass particulates $(<1 \mathrm{~mm})$, chalk particulates and fibres persisted on vehicle seats after cleaning as these were particulates of interest in the criminal case in question. The experiment also sought to compare the differential tenacity of the different particulates and to establish whether 
it would be possible for fibre evidence to remain on the vehicle seat after it was cleaned whilst the glass and chalk evidence was differentially removed as this was an important issue in the criminal investigation.

The three forms of trace evidence were applied to four clean vehicle seats which had previously been divided into five equal sections $(10 \times 25 \mathrm{~cm})$ for accurate tapings to be taken throughout the course of the experiment. A person wearing protective clothing sat on each seat for five minutes to simulate a short drive. The first section of each vehicle seat was then taped. An industrial vacuum cleaner was then used to clean each seat for 10 seconds and the second section was taped. This was followed by a third taping after another 10 seconds of vacuuming, and a fourth taping taken after a further 20 seconds of vacuuming. A final taping was taken after an additional 20 seconds of vacuum cleaning. These results are presented in Table 2 and Figure 5. By the end of this cleaning process there was no trace evidence visible to the naked eye yet as figure 5 shows, all three forms of trace physical evidence are still present on the vehicle seats after 60 seconds of sustained cleaning.

Figure 5 portrays the persistence of the three different particulates on the vehicle seats and demonstrates the classic trace evidence decay curve where an initial period of rapid loss takes place followed by subsequent period of less rapid decay. Whilst glass and chalk particulates behaved in a similar manner (Figure 5A and 5C) with $11 \%$ and $14 \%$ remaining after 60 seconds of vacuum cleaning, the fibres (Figure 5B) exhibited a slower rate of decay with $44 \%$ remaining. Thus whilst glass and chalk particulates exhibit tenacity on vehicle seats that have been cleaned, fibres exhibit even greater tenacity.

This procedure was repeated a further two times on identical seats (seats 3 and 4) with glass particulates but with longer periods of cleaning undertaken between tapings (20, 40,80 and 120 seconds). It must be stressed that the vacuum cleaning process was undertaken on a very small area of the seat for up to 120 seconds and in order to clean the entire seat in such a thorough manner it is estimated that it would take up to 20 minutes per seat. These results are presented in Table 3. 
Table 4 presents the mean values of glass particulate persistence on the four seats tested for varying periods of vacuum cleaning. It is significant that even after 60 seconds of cleaning, glass particulates remain $(3.5 \%$ and $18.5 \%$ on the seat and back respectively). However, after 120 seconds there are very few particulates present on the seats $(0.7 \%$ and $0.1 \%$ on the seat and back of the driver seat respectively). Figure 6 portrays these findings graphically and demonstrates that glass particulates exhibit a similar decay curve to the previous experiment despite the longer periods of cleaning.

\subsubsection{Implications for the criminal case}

The results from experiments 1 and 2 indicate that it is highly likely that, under normal circumstances, a transfer of glass particulates onto the person who smashed the window would indeed occur. Experiment 2 shows that not only will glass particulates be transferred onto the clothing of a person breaking a window pane, but also demonstrates that such glass particulates may well persist long enough for the subsequent transfer of some of those particulates to a vehicle seat. Experiment 3 demonstrates the tenacity of both glass, chalk and fibre particulates during vacuum cleaning and shows that whilst fibres exhibit greater tenacity than glass and chalk particulates, there are still a large number of glass and chalk particulates present after 60 seconds of vacuuming a $25 \times 10 \mathrm{~cm}$ area. Indeed, there are still a very small number of glass particulates present after 120 seconds of vacuuming. These findings were crucial to the interpretation of the trace physical evidence collected from the pertinent scenes associated with this crime. In this court case, there were no glass particulates recovered from the clothing or the vehicle belonging to the suspect. This experimental work demonstrates the difficulty in explaining such a lack of glass evidence even if vacuuming of the vehicle had taken place. Whilst inferences can be made in the light of the established literature, the evidential weight of the trace evidence greatly increases when couched within the forensic framework established by the secondary experimental studies carried out specifically for this case.

\section{Conclusions}

Specific and repeatable experimental studies (at both the primary and secondary level) that mimic forensic reality have an important role to play in forensic investigations. 
At the primary level, such studies contribute to establishing a sound body of theory in forensic science, whilst secondary level experimentation can complement these previous findings by providing specific insight into particular cases to enable more accurate interpretations of trace physical evidence in a specific instance.

Experimental studies can enable more accurate collection and sampling procedures as well as indicate what form of analysis will prove to be the most efficacious and appropriate in the specific forensic context. Indeed, in certain situations, secondary level experimental work may afford the trace physical evidence more weight in the courtroom as the specific forensic context can be taken into account. The establishment of general principles and theory is still of great importance, but the use of secondary level experimental studies may have great value in providing additional confirmation, or indeed in identifying important variables that may not have been previously considered. It is recognised that the down side of such an approach is that of both time and cost. However, the better the understanding of the context within which we are working as forensic scientists, the better we will be able to collect, analyse and interpret the trace physical evidence that comes to light during the course of an investigation.

\section{References}

[1]Morgan, R. M., Freudiger-Bonzon, J., Nichols, K. H., Jellis, T., Dunkerley, S., Zelazowski, P. and Bull, P. A The geoforensic analysis of soils from footwear. In Ritz, K., Dawson, L. and Miller, D. (Eds) Criminal and Environmental Soil Forensics. Springer. 2008

[2]Curran, J. M., Hicks, T. N., Buckleton, J. S. Forensic Interpretation of Glass Evidence CRC Press. 2000

[3] Caddy, B. (Ed) Trace Evidence Analysis and Interpretation: Glass and Paint. Taylor and Francis 2001.

[4] Robertson, J. (ed) Forensic Examination of Human Hair. Taylor \& Francis 1999 [5]Bodziak, W. Footwear Impression Evidence: Detection, Recovery, and Examination (Practical Aspects of Criminal \& Forensic Investigations) CRC Press. 1999

[6]Meyers, M. S., and Foran, D. R. Spatial and temporal influences on bacterial profiling of forensic soil samples. Journal of Forensic Sciences 53(3) (2008): 652660

[7]Schultz, J. J. Sequential monitoring of burials containing small pig cadavers using ground penetrating radar. Journal of Forensic Sciences 53(2) (2008): 279-287

[8]Heath, L.E. and Saunders, V. A. Spatial variation in bacterial DNA profiles for forensic soil comparisons Journal of the Canadian Society of Forensic Science 41 (1) (2008): 29-37 
[9]Benninger, L. A., Carter, D. O. and Forbes, S. L. The biochemical alteration of soil beneath a decomposing carcass. Forensic Science International 180 (2-3) (2008): 7075

[10]Morgan, R. M., Allen, E., Lightowler, Z. L., Freudiger-Bonzon, J. and Bull, P. A. A forensic geoscience framework and practice. Policing: A Journal of Policy and Practice 2 (2008):185-195

[11]Riding, J. B., Rawlins, B. G. and Coley, K. H. Changes in soil pollen assemblages on footwear worn at different sites. Palynology 31 (2007): 135-151

[12]Zavada, M. S., McGraw, S. M. and Miller, M. A. The role of clothing fabrics as passive pollen collectors in the north-eastern United States. Grana 46(4) (2007):285291

[13]Walls, H. J. Forensic Science London Sweet and Maxwell 1968

[14]Morgan, R. M. and Bull, P. A. The philosophy, nature and practice of forensic geoscience. Progress in Physical Geography 31(2007):43-58

[15]Nelson, D. F. and Revell, B. C. Backward fragmentation from breaking glass.

Journal of the Forensic Science Society 7 (1967): 58

[16]Pounds, C. A. \& Smalldon, K. W. The distribution of glass fragments in front of a broken window and the transfer of fragments to individuals standing nearby. $J$.

Forens. Sci. Soc 18(1978):197-203

[17]Luce, R. J. W., Buckle, J. L. and McInnis, I. A study on the backward fragmentation of window glass and the transfer of glass fragments to individual's clothing. Journal of the Canadian Society of Forensic Science 1991; 24 (2): 79-89 [18]Locke, J. \& Unikowski, J. A. Breaking of flat glass - Part 1: Size and distribution of particles from plain glass windows. Forensic Science International, 51 (1991): 251-262

[19] Allen, T. J. and Scranage, J. K. The transfer of glass - part 1: transfer of glass to individuals at different distances. Forensic Science International 93(1998): 167-174. [20]Hicks, T., Schutz, F., Curran, J. M. and Triggs, C. M. A model for estimating the number of glass fragments transferred when breaking a pane: experiments with firearms and hammer. Science and Justice 45(2) (2005): 65-74

[21] Hicks, T., Vanina, R. and Margot, P. Transfer and Persistence of Glass Fragments on Garments. Science and Justice 1996; 36 (2): 101-107

[22] Allen, T. J., Hoefler, K. and Rose, S. J. The transfer of glass - part 2: the study of the transfer of glass to a person by various methods. Forensic Science International; 93 (1998): 175-193.

[23]Allen, T. J., Hoefler, K. and Rose, S. J. The transfer of glass - part 3: the transfer of glass from a contaminated person to another uncontaminated person during a ride in a car. Forensic Science International 93 (1998): 195-200.

[24] Pounds, C. A. and Smalldon, K. W. The transfer of fibres between clothing materials during simulated contacts and their persistence during wear, part I - Fibre transference. Journal of the Forensic Science Society 15(1975): 17-27.

[25] Pounds, C. A. and Smalldon, K. W. The transfer of fibres between clothing materials during simulated contacts and their persistence during wear, part II. Journal of the Forensic Science Society 15(1975): 29-37

[26] Pounds, C. A. and Smalldon, K. W. The transfer of fibres between clothing materials during simulated contacts and their persistence during wear, part III - a preliminary investigation of the mechanisms involved. Journal of the Forensic Science Society 15(1975): 197-207

[27]Robertson, J. and Grieve, M. (ed.) Forensic Examination of Fibres. Taylor and Francis 1999 
[28]Robertson, C., Kidd, B.M. and Parkinson, H. M. P. The persistence of Textile Fibres Transferred during Simulated Contacts. Journal of Forensic Science Society 22 (1982):353-360

[29]Robertson, J. and Olaniyan, D. Effect of garment cleaning on the recovery and redistribution of transferred fibres. Journal of Forensic Sciences 31(1) (1986): 73-78 [30]Roux, C., Chable, J. and Margot, P. Fibre transfer experiments onto car seats. Science and Justice 36 (1996): 143-151

[31]Roux, C., Langdon, S., Wraight, D. and Robertson, J. The transfer and persistence of automotive carpet fibres on shoe soles. Science and Justice 39(1999): 239-251 [32]Salter, M. T. and Cook, R. Transfers of fibres to head hair, their persistence and retrieval. Forensic Science International 81(2-3) (1996):211-221

[33]Wiggins, K. G., Emes, A. and Brackley, L. H. The transfer and persistence of small fragments of polyurethane foam onto clothing. Science and Justice 42(2002):105-110

[34] Dachs, J., McNaught, L. J. and Robertson, J. The persistence of human scalp hair on clothing fabrics. Forensic Science International 138(2003):27-36

[35]Gaudette, B. D. Hair transfer, persistence and recovery. In Siegal, J. A., (ed in chief) Encyclopedia of Forensic Sciences. Academic Press. 2000 pp1032-1034.

[36]Bull, P. A., Morgan, R. M., Sagovsky, A. and Hughes, G. J. A. The Transfer and Persistence of Trace Particulates: Experimental studies using clothing fabrics.

Science and Justice. 46(3) (2006):182-191

[37]Brewster, F., Thorpe, J., Gettinby, G. and Caddy, B. 1985 The retention of glass particles on woven fabrics. Journal of Forensic Sciences 30(3)( 1985):798-805.

[38]Locke, J. \& Unikowski, J. A. Breaking of flat glass - Part 2: Effect of pane parameters on particle distribution. Forensic Science International 56(1992): 95-106

\section{List of Figures}

Figure 1 Numbers of mineral particulates recovered from each item for each experimental run

Figure 2 Average number of mineral particulates recovered after washing $(n=3)$

Figure 3 Rose diagrams to depict the spatial distribution of glass fragments produced when smashing a window.

$\mathrm{A}$ and $\mathrm{B} . \quad 6 \mathrm{~mm}$ old glass

$\mathrm{C}$ and $\mathrm{D}$. $\quad 6 \mathrm{~mm}$ new glass

E, F, G, H, I, J. 4mm new glass

Figure 4 The proportion of glass particulates recovered from the t-shirt during the course of experiment 2. 1. represents immediately following the window break; 2. after five minutes walk; 3 . after a further five minute walk; 4 . after a five minute run; 5. after a further five minute run; 6 . after machine washing and drying.

Figure 5 The percentage of glass, fibre and chalk particulates retained on two vehicle seats after different periods of vacuum cleaning.

Figure 6 A graph to show the average percentage of glass particulates retained on the back and seat of each vehicle seat in experiment 3. 


\section{List of Tables}

Table 1 The number of glass fragments recovered from the t-shirt during the course of experiment 2 .

Table 2 The percentage of particulates retained on four vehicle seats after different periods of vacuum cleaning.

Table 3 The percentage of glass particulates retained on seats 3 and 4 after different periods of vacuum cleaning.

Table 4 The average percentage of glass particulates retained on the back and seat of each vehicle seat in experiment 3 . 


\begin{tabular}{|c|c|c|c|c|c|c|}
\hline $\begin{array}{l}\text { Experimental } \\
\text { Run }\end{array}$ & Item & $<10 \mu \mathrm{m}$ & $\begin{array}{l}10- \\
100 \mu \mathrm{m}\end{array}$ & $\begin{array}{l}101- \\
1000 \mu \mathrm{m}\end{array}$ & $>1000 \mu \mathrm{m}$ & total \\
\hline \multirow[t]{4}{*}{1} & Left Trainer & 33 & 8 & 1 & 5 & 47 \\
\hline & Right Trainer & 27 & 6 & 7 & 2 & 42 \\
\hline & T-Shirt & 5 & 7 & 2 & 0 & 14 \\
\hline & Jeans & 10 & 28 & 4 & 1 & 43 \\
\hline \multirow[t]{4}{*}{2} & Left Trainer & 38 & 25 & 5 & 2 & 70 \\
\hline & Right Trainer & 55 & 12 & 6 & 1 & 74 \\
\hline & T-Shirt & 90 & 33 & 3 & 0 & 126 \\
\hline & Jeans & 84 & 21 & 3 & 1 & 109 \\
\hline \multirow[t]{4}{*}{3} & Left Trainer & 18 & 12 & 5 & 4 & 39 \\
\hline & Right Trainer & 84 & 16 & 4 & 3 & 107 \\
\hline & T-Shirt & 231 & 89 & 4 & 1 & 325 \\
\hline & Jeans & 214 & 73 & 11 & 3 & 301 \\
\hline
\end{tabular}

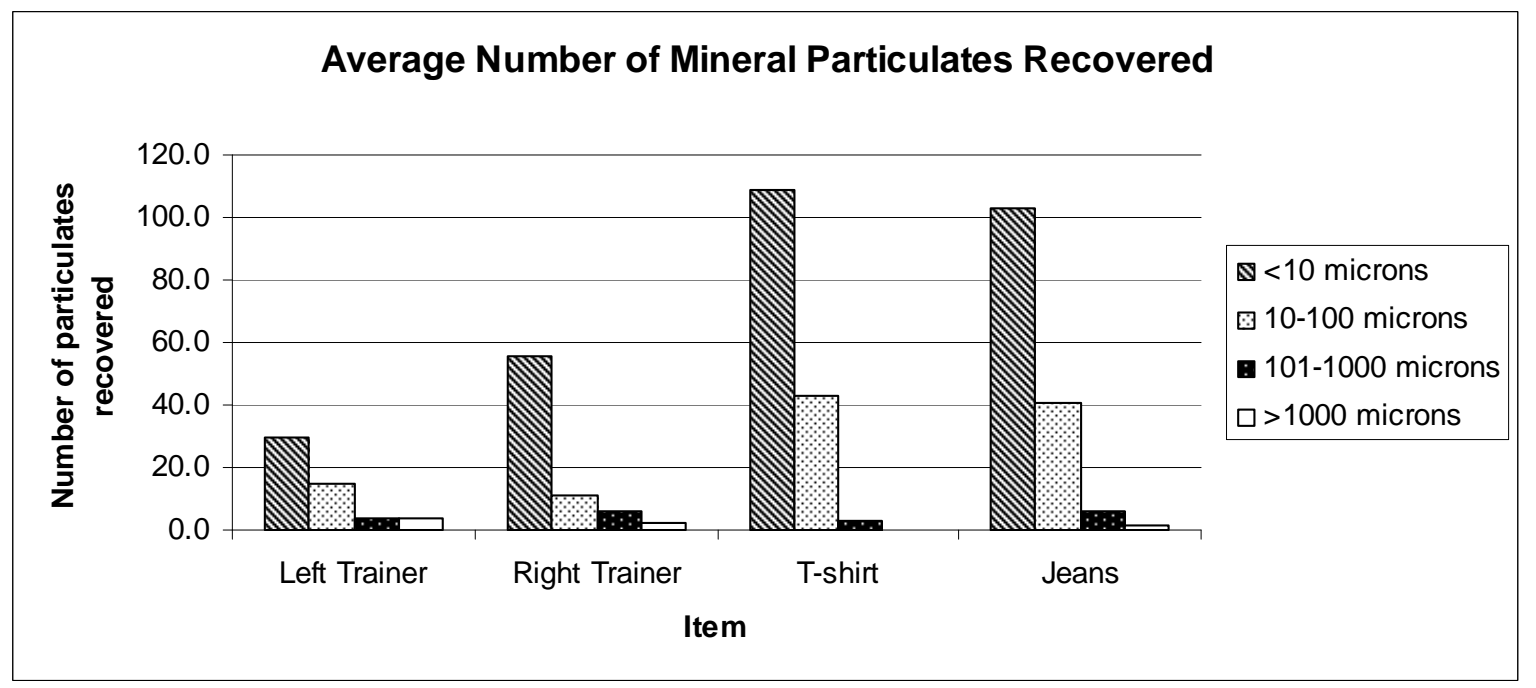

Figure 1a Numbers of mineral particulates recovered from each item for each experimental run 


\begin{tabular}{|c|c|c|c|c|c|c|}
\hline $\begin{array}{l}\text { Experimental } \\
\text { Run }\end{array}$ & Item & $<10 \mu \mathrm{m}$ & $\begin{array}{l}10- \\
100 \mu \mathrm{m}\end{array}$ & $\begin{array}{l}101- \\
1000 \mu \mathrm{m}\end{array}$ & $>1000 \mu \mathrm{m}$ & total \\
\hline \multirow[t]{4}{*}{1} & Left Trainer & 0 & 0 & 0 & 0 & 0 \\
\hline & Right Trainer & 0 & 0 & 0 & 0 & 0 \\
\hline & T-Shirt & 0 & 0 & 0 & 1 & 1 \\
\hline & Jeans & 0 & 0 & 0 & $\overline{0}$ & $\overline{0}$ \\
\hline \multirow[t]{4}{*}{2} & Left Trainer & 0 & 1 & 0 & 0 & 1 \\
\hline & Right Trainer & 0 & 0 & 0 & $\overline{0}$ & $\overline{0}$ \\
\hline & T-Shirt & 0 & 4 & 2 & 1 & 7 \\
\hline & Jeans & 0 & 0 & 0 & 0 & 0 \\
\hline \multirow[t]{4}{*}{3} & Left Trainer & 0 & 0 & 0 & 0 & 0 \\
\hline & Right Trainer & 2 & 0 & 0 & 1 & 3 \\
\hline & T-Shirt & 0 & 1 & 1 & 1 & 3 \\
\hline & Jeans & 0 & 0 & 4 & 1 & 5 \\
\hline
\end{tabular}

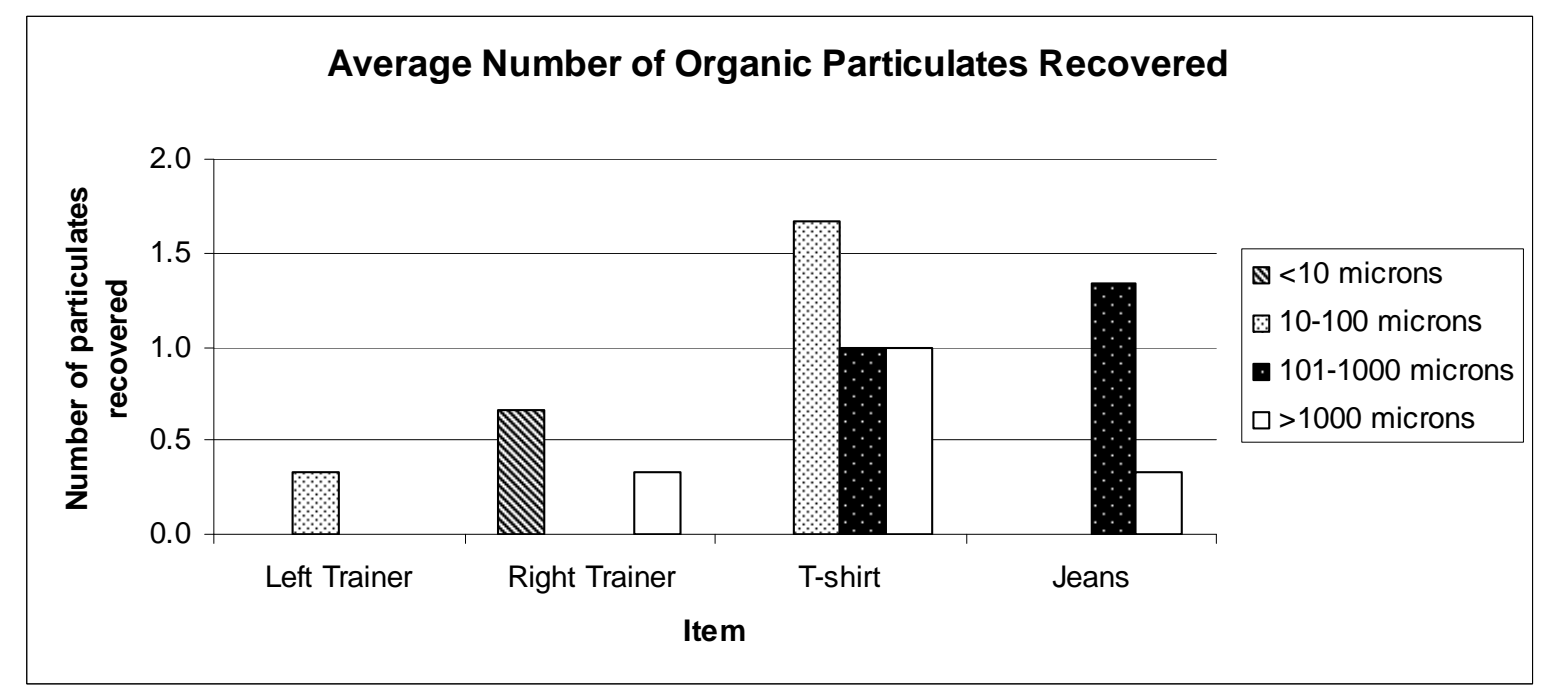

Figure $1 \mathrm{~b}$ Numbers of organic particulates recovered from each item for each experimental run 


\begin{tabular}{|c|c|c|c|c|c|}
\hline & & $<10 \mu \mathrm{m}$ & $10-100 \mu \mathrm{m}$ & $101-1000 \mu \mathrm{m}$ & $>1000 \mu \mathrm{m}$ \\
\hline \multirow{2}{*}{$\begin{array}{c}\text { All } \\
\text { items }\end{array}$} & Mean & 61.5 & 28.4 & 7.0 & 3.1 \\
\hline & $\mathrm{Sd}$ & 17.8 & 15.5 & 5.3 & 3.7 \\
\hline \multirow{2}{*}{$\begin{array}{c}\text { Left } \\
\text { Trainer }\end{array}$} & Mean & 56.9 & 27.8 & 7.4 & 7.9 \\
\hline & $\mathrm{Sd}$ & 12.2 & 9.7 & 5.3 & 4.4 \\
\hline \multirow{2}{*}{$\begin{array}{c}\text { Right } \\
\text { Trainer }\end{array}$} & Mean & 72.4 & 15.2 & 9.5 & 3.0 \\
\hline & $\mathrm{Sd}$ & 7.3 & 1.0 & 6.6 & 1.7 \\
\hline \multirow[t]{2}{*}{ T-shirt } & Mean & 59.4 & 34.5 & 6.0 & 0.1 \\
\hline & $\overline{\mathrm{Sd}}$ & 20.5 & 13.4 & 7.2 & 0.2 \\
\hline \multirow[t]{2}{*}{ Jeans } & Mean & 57.1 & 36.2 & 5.2 & 1.4 \\
\hline & $\mathrm{Sd}$ & 29.5 & 25.2 & 3.5 & 0.8 \\
\hline
\end{tabular}

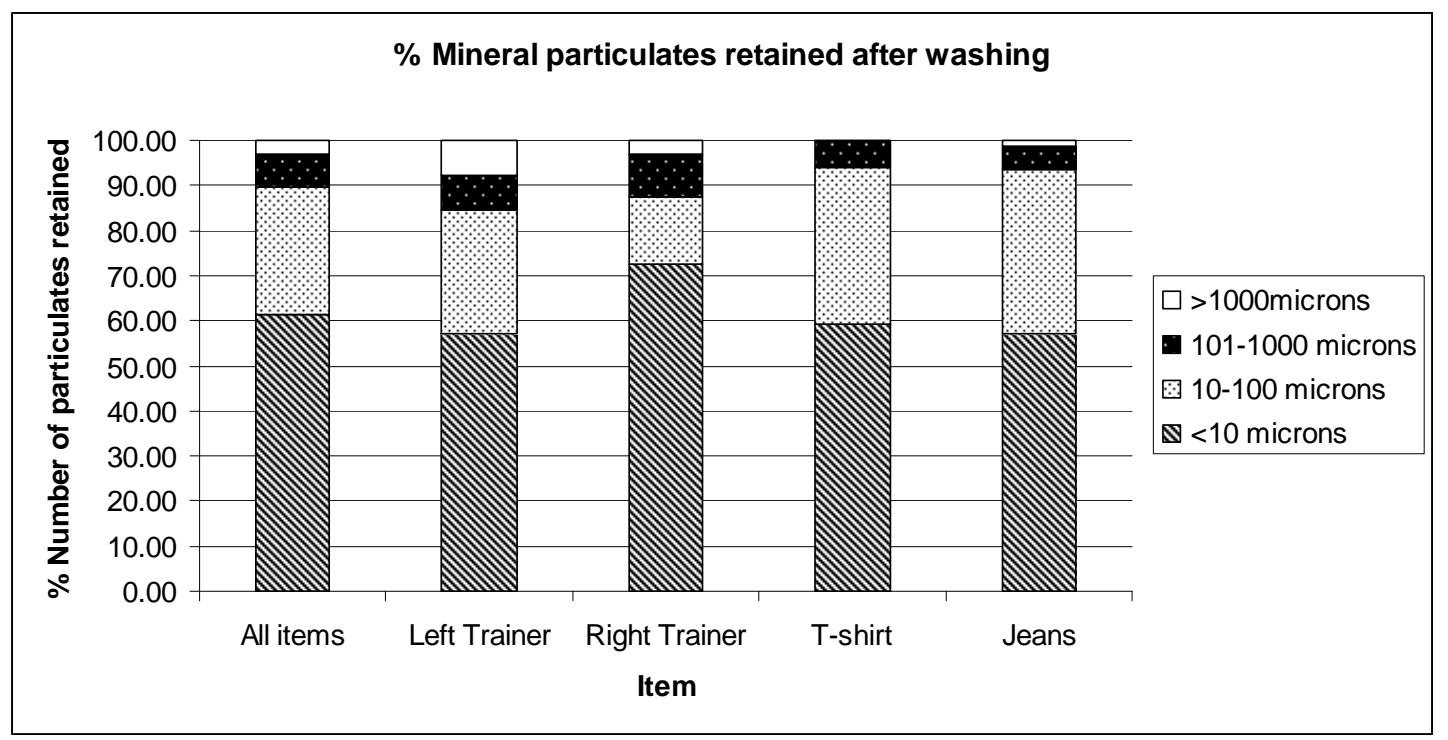

Figure 2 Average number of mineral particulates recovered after washing $(n=3)$ 


\begin{tabular}{|c|c|c|c|}
\hline $\begin{array}{c}\text { Tape } \\
\text { Number }\end{array}$ & $\begin{array}{c}\text { Time of } \\
\text { taping }\end{array}$ & $\begin{array}{c}\text { Number of glass particulates } \\
\text { recovered from the t-shirt } \\
\text { (Pane 1) }\end{array}$ & $\begin{array}{c}\text { Number of glass particulates } \\
\text { recovered from the t-shirt } \\
\text { (Pane 2) }\end{array}$ \\
\hline 1 & $\begin{array}{c}\text { Window } \\
\text { Break }\end{array}$ & 12 & 34 \\
\hline 2 & Walk 1 & 4 & 7 \\
\hline 3 & Walk 2 & 3 & 3 \\
\hline 4 & Run 1 & 2 & 4 \\
\hline 5 & Run 2 & 1 & 1 \\
\hline 6 & Wash and & 1 & \\
\hline
\end{tabular}

Table 1 The number of glass fragments recovered from the t-shirt during the course of experiment 2 .

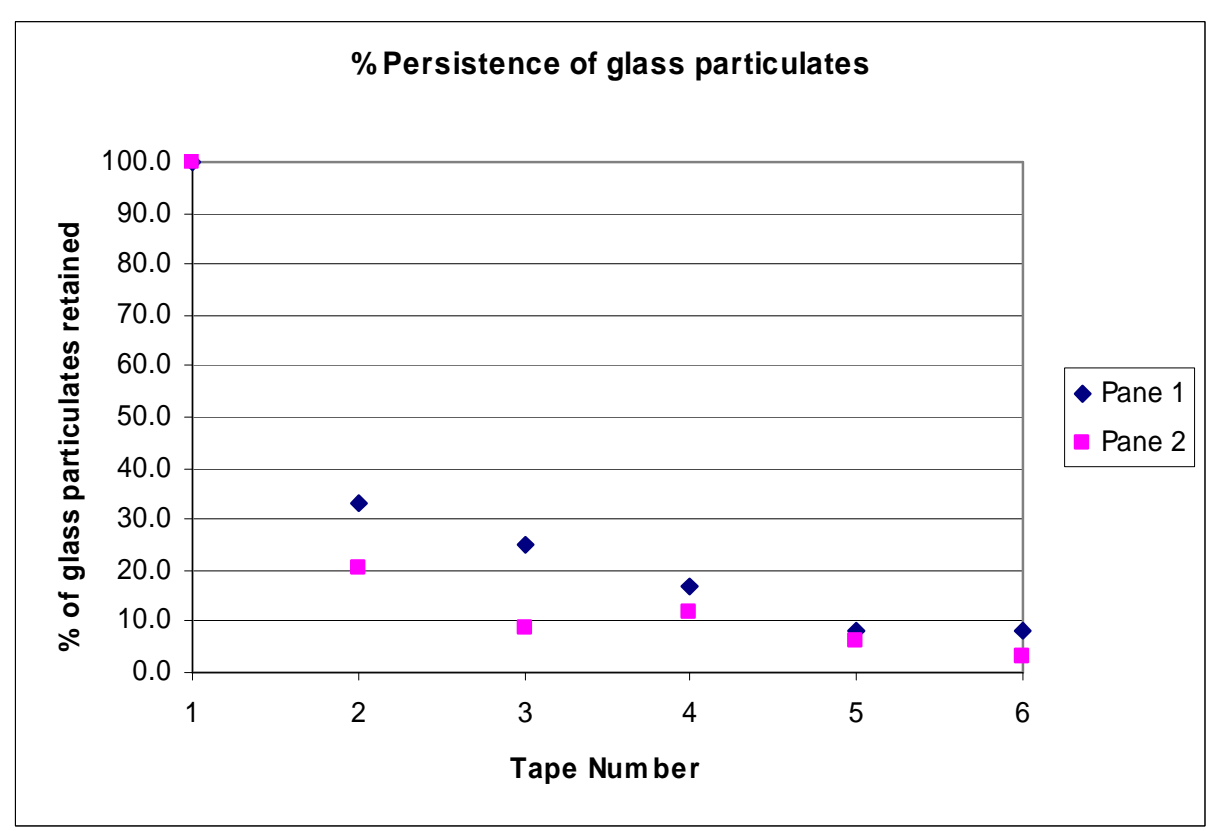

Figure 4 The proportion of glass particulates recovered from the t-shirt during the course of experiment 2. 1. represents immediately following the window break; 2 . 
after five minutes walk; 3. after a further five minute walk; 4 . after a five minute run; 5. after a further five minute run; 6 . after machine washing and drying. 


\begin{tabular}{|l|l|c|c|c|c|c|}
\hline & & \multicolumn{5}{|c|}{ Length of vacuuming (seconds) } \\
\hline \multirow{3}{*}{ Seat 1 - seat } & & $\mathbf{0}$ & $\mathbf{1 0}$ & $\mathbf{2 0}$ & $\mathbf{4 0}$ & $\mathbf{6 0}$ \\
\cline { 2 - 7 } & Glass & 100 & 32 & 14 & 8 & 3 \\
\cline { 2 - 7 } & Fibres & 100 & 55 & 33 & 33 & 55 \\
\cline { 2 - 7 } & Chalk & 100 & 58 & 21 & 21 & 13 \\
\hline Seat 1 - back & Glass & 100 & 56 & 31 & 26 & 14 \\
\cline { 2 - 7 } & Fibres & 100 & 100 & 57 & 43 & 71 \\
\cline { 2 - 7 } & Chalk & 100 & 25 & 25 & 50 & 25 \\
\hline & Glass & 100 & 62 & 20 & 6 & 4 \\
\cline { 2 - 7 } & Fibres & 100 & 50 & 57 & 79 & 21 \\
\cline { 2 - 7 } & Chalk & 100 & 39 & 29 & 11 & 4 \\
\hline \multirow{3}{*}{ Seat 2 - back } & Glass & 100 & 53 & 34 & 47 & 23 \\
\cline { 2 - 7 } & Fibres & 100 & 57 & 57 & 43 & 29 \\
\cline { 2 - 7 } & Chalk & 100 & 50 & 13 & 0 & 13 \\
\hline
\end{tabular}

Table 2 The percentage of particulates retained on four vehicle seats after different periods of vacuum cleaning.

\begin{tabular}{|l|c|c|c|c|c|}
\hline & \multicolumn{5}{|c|}{ Length of vacuuming (seconds) } \\
\hline & $\mathbf{0}$ & $\mathbf{2 0}$ & $\mathbf{4 0}$ & $\mathbf{8 0}$ & $\mathbf{1 2 0}$ \\
\hline Seat 3 - seat & 100 & 17 & 4 & 1 & 1 \\
\hline Seat 3 - back & 100 & 5 & 0.1 & 0.1 & 0.1 \\
\hline Seat 4 - seat & 100 & 1 & 0.1 & 0.1 & 0.1 \\
\hline Seat 4 - back & 100 & 17 & 0.5 & 0.1 & 0.1 \\
\hline
\end{tabular}

Table 3 The percentage of glass particulates retained on seats 3 and 4 after different periods of vacuum cleaning. 


\begin{tabular}{|l|c|c|c|c|c|c|c|}
\hline & \multicolumn{7}{|c|}{ Length of vacuuming (seconds) } \\
\hline $\begin{array}{l}\text { Part of seat } \\
\text { taped }\end{array}$ & $\mathbf{0}$ & $\mathbf{1 0}$ & $\mathbf{2 0}$ & $\mathbf{4 0}$ & $\mathbf{6 0}$ & $\mathbf{8 0}$ & $\mathbf{1 2 0}$ \\
\hline Seat & 100 & 47 & 13. & 4.5 & 3.5 & 1.2 & 0.7 \\
\hline Back & 100 & 54.5 & 21.7 & 18.3 & 18.5 & 0.1 & 0.1 \\
\hline
\end{tabular}

Table 4 The average percentage of glass particulates retained on the back and seat of each vehicle seat in experiment 3. 

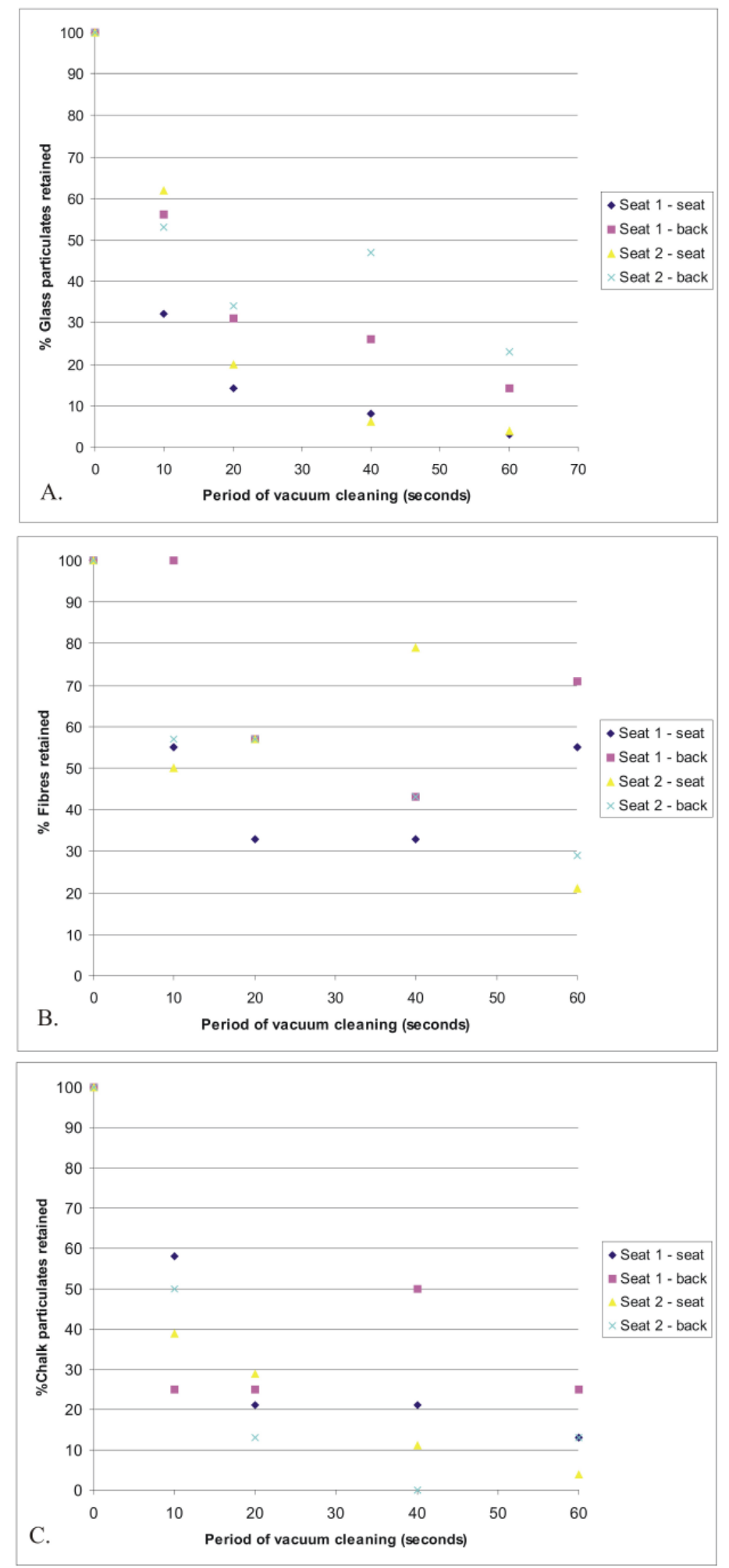

Figure 5 The percentage of glass, fibre and chalk particulates retained on two vehicle seats after different periods of vacuum cleaning. 


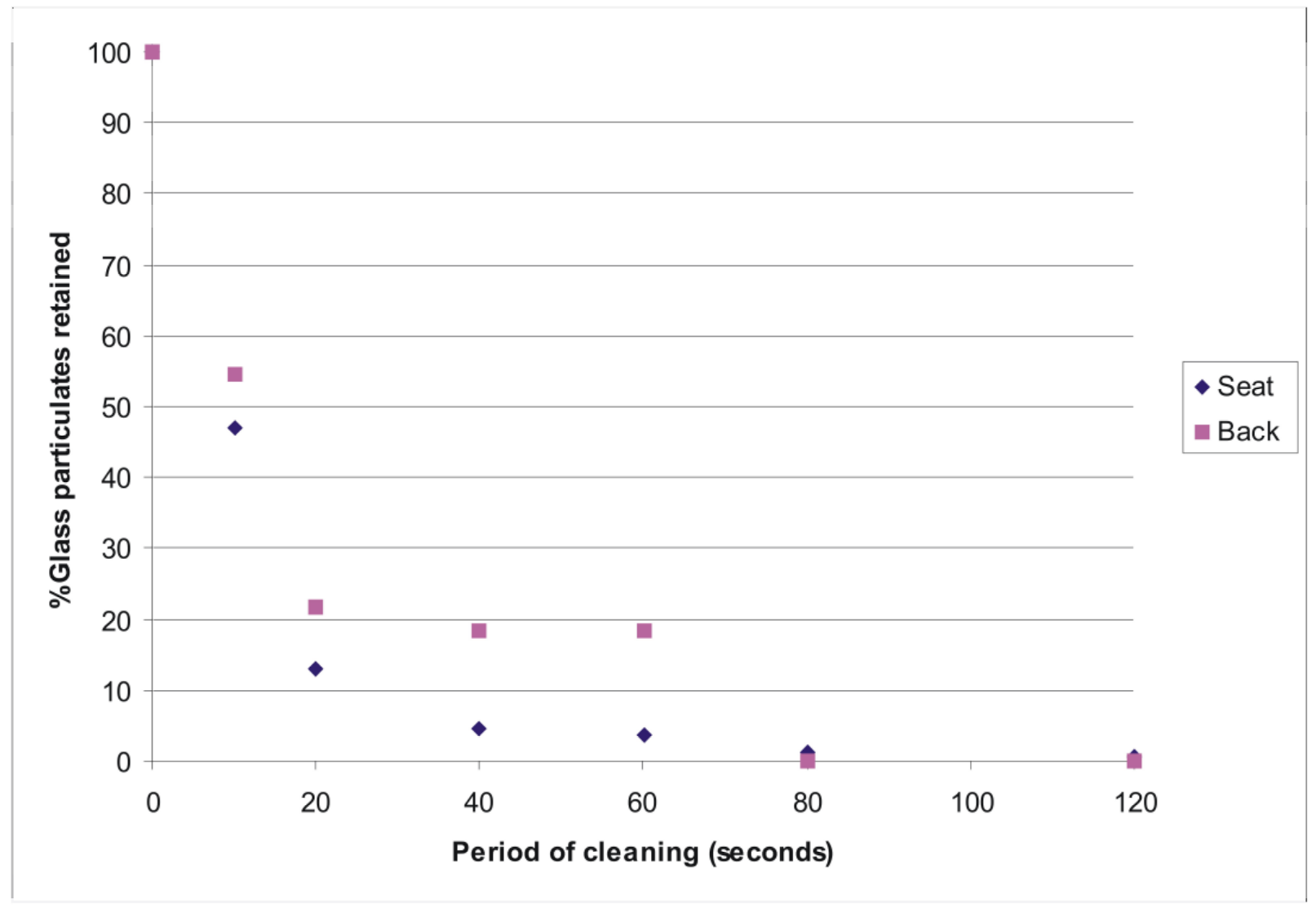

Figure $6 \mathrm{~A}$ graph to show the average percentage of glass particulates retained on the back and seat of each vehicle seat in experiment 3. 